Article

\title{
Functional Expression and Characterization of a Panel of Cobalt and Iron-Dependent Nitrile Hydratases
}

\author{
Birgit Grill ${ }^{1}$, Maximilian Glänzer ${ }^{1}$, Helmut Schwab ${ }^{1}$, Kerstin Steiner ${ }^{1}$, Daniel Pienaar ${ }^{2}$, \\ Dean Brady $\left.{ }^{2} \mathbb{(}\right)$, Kai Donsbach ${ }^{3}$ and Margit Winkler ${ }^{1,4, * \mathbb{D}}$ \\ 1 Austrian Center of Industrial Biotechnology GmbH, $8010 \mathrm{Graz}$, Austria; birgit.grill@tugraz.at (B.G.); \\ maximilian.glaenzer@student.tugraz.at (M.G.); helmutschwab@acib.at (H.S.); kerstin.steiner@acib.at (K.S.) \\ 2 Molecular Science Institute, School of Chemistry, University of the Witwatersrand, P.O. Wits 2050, \\ Johannesburg, South Africa; daniel.pienaar@wits.ac.za (D.P.); Dean.Brady@wits.ac.za (D.B.) \\ 3 PharmaZell, 83064 Raubling, Germany; kai.donsbach@pharmazell.com \\ 4 Institute of Molecular Biotechnology, Graz University of Technology, NAWI Graz, 8010 Graz, Austria \\ * Correspondence: margitwinkler@acib.at; Tel.: +43-316-873-9333
}

Academic Editor: Roberto Fernandez-Lafuente

Received: 7 May 2020; Accepted: 26 May 2020; Published: 28 May 2020

\begin{abstract}
Nitrile hydratases (NHase) catalyze the hydration of nitriles to the corresponding amides. We report on the heterologous expression of various nitrile hydratases. Some of these enzymes have been investigated by others and us before, but sixteen target proteins represent novel sequences. Of 21 target sequences, 4 iron and 16 cobalt containing proteins were functionally expressed from Escherichia coli BL21 (DE3) Gold. Cell free extracts were used for activity profiling and basic characterization of the NHases using the typical NHase substrate methacrylonitrile. Co-type NHases are more tolerant to high $\mathrm{pH}$ than Fe-type NHases. A screening for activity on three structurally diverse nitriles was carried out. Two novel Co-dependent NHases from Afipia broomeae and Roseobacter sp. and a new Fe-type NHase from Gordonia hydrophobica were very well expressed and hydrated methacrylonitrile, pyrazine-carbonitrile, and 3-amino-3-( $p$-toluoyl)propanenitrile. The Co-dependent NHases from Caballeronia jiangsuensis and Microvirga lotononidis, as well as two Fe-dependent NHases from Pseudomonades, were-in addition — able to produce the amide from cinnamonitrile. Summarizing, seven so far uncharacterized NHases are described to be promising biocatalysts.
\end{abstract}

Keywords: nitrile hydratase (NHase); nitrile; amide; metalloprotein; non-heme iron; non-corrinoid cobalt; biocatalysis; active pharmaceutical ingredient.

\section{Introduction}

Nitrile hydratases (NHase; EC 4.2.1.84) catalyze the hydration of nitriles to the corresponding amides (Figure 1a) [1]. Due to the broad substrate acceptance of NHases, numerous amides are accessible from their respective nitrile precursors [2]. The first example of an industrial bioconversion process for the manufacturing of the commodity chemical acrylamide involved NHase in a microbial host [3]. Nicotinamide and 5-cyanoveleramide are also products made on a commercial production scale with NHase biocatalysts [4]. Another important field of application of these enzymes is the bioremediation of contaminating nitriles [5]. A review from earlier this year summarizes NHase research from recent years, including the natural distribution, gene types, post-translational modifications, expression, proposed catalytic mechanism, biochemical properties, and potential applications of NHases [4]. Briefly, two types of NHases can be distinguished, the non-corrin cobalt-containing and non-heme iron-containing NHases. Both types are composed of an $\alpha$ - and a $\beta$-subunit and functional heterologous expression depends on the action of an accessory protein [6,7]. Successful heterologous expression has been described for the NHases from Klebsiella oxytoca [8], Bacillus sp. RAPc [9], and the 
thermostable NHases from Pseudonocardia thermophila [10], Pseudomonas putida [6], and Aurantimonas manganoxydans [11]. However, limited acceptability of substrates, low expression levels, and instability under process relevant conditions may still hamper practical applications of NHase biocatalysts.

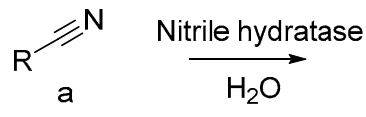

(a)

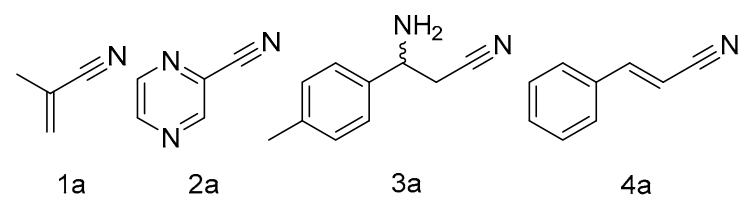

(b)

Figure 1. (a) Reaction scheme; (b) substrates investigated in this study.

Herein we explored the sequence space, cloned, and expressed a few known and sixteen so far uncharacterized proteins with sequence similarity to nitrile hydratases. The investigated panel consists of seven Fe-type NHases and 16 Co-type NHases. Functional expression and basic characterization regarding substrate scope and selected biochemical characteristics are reported.

\section{Results and Discussion}

\subsection{Identification and Production of Nitrile Hydratases}

With the aim to identify new nitrile hydratases, we looked for described NHase enzymes in the literature and in databases (NCBI, pdb). Reported heterologous expression in Escherichia coli and high thermostability were favored properties of literature-known NHases. In addition, the sequences of the well-studied iron-type ReNHase and cobalt-type BrNHase were used as templates for a blastp search against the non-redundant GenBank protein sequences. Several sequences, assigned as (putative) nitrile hydratases, were subjected to computational analysis regarding presence of a respective (putative) accessory protein, lack of transmembrane regions and PEST motifs (proline, glutamate, serine, and threonine rich motives which may cause rapid protein degradation), and the optimal growth temperature of their source organism, whereby enzymes of psychrophilic organisms were rejected. We selected diverse sequences as summarized in Figure 2. The NHase genes were cloned into the pMS470 vector and expressed under the control of the tac promoter in E. coli in the presence of their putative accessory proteins. The active site metal was supplemented at the time of induction of gene expression. The expression temperature was $20^{\circ} \mathrm{C}$ to facilitate protein folding and metal incorporation. 
Tree scale: $0.1 \longmapsto$

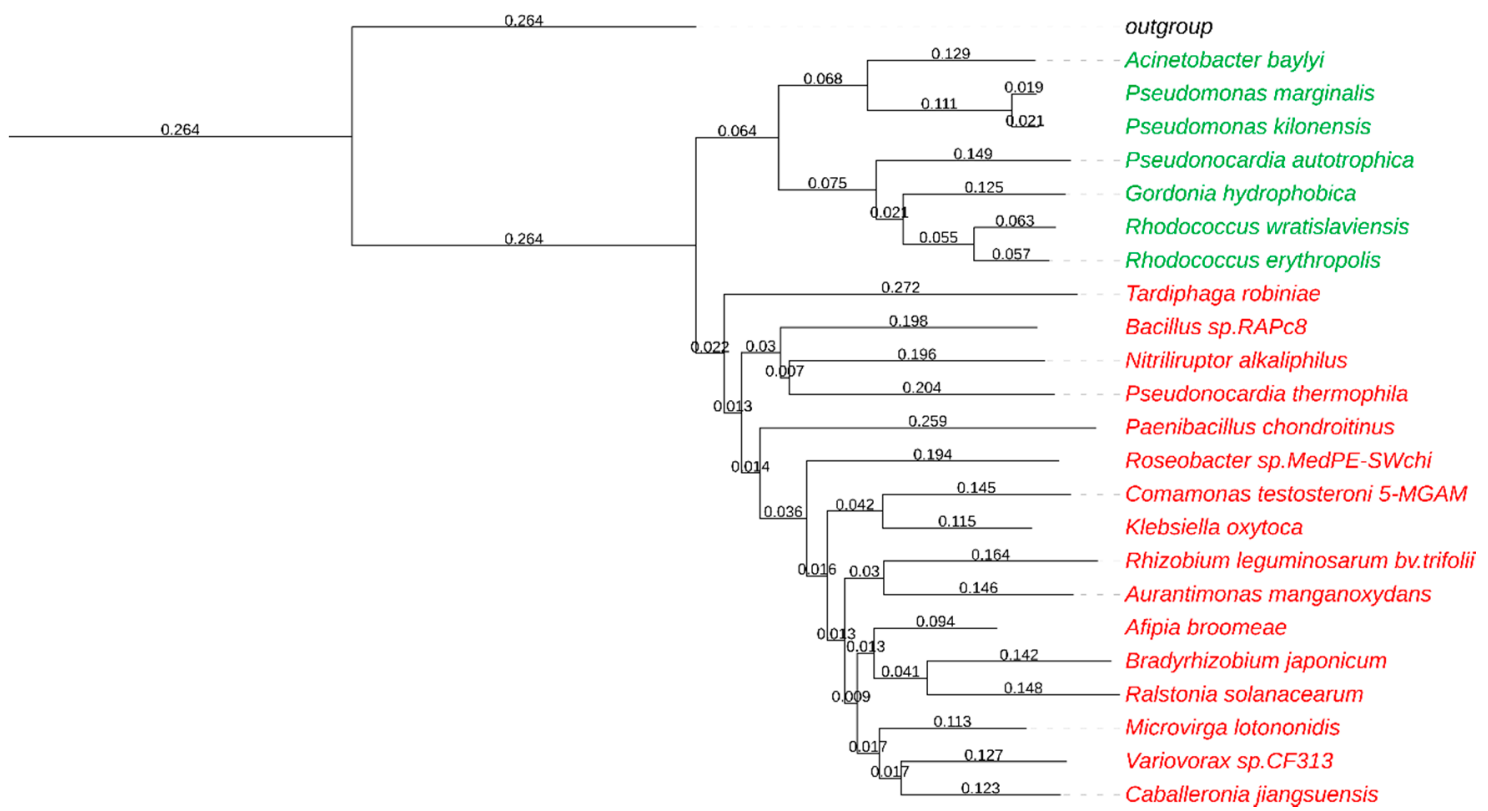

Figure 2. Phylogenetic relationship of nitrile hydratase (NHase) $\alpha$-subunits based on a protein distance analysis with T-COFFEE (Version_11.00.d625267) and visualization with iTOL (Version 5.5.1) [12]. Rhodococcus erythropolis amidase (Uniprot: P22984.2) served as the outgroup. Iron-type NHases are displayed in green, cobalt-type NHases in red.

High expression levels were achieved for Microvirga lotononidis NHase (MlNHase), Paenibacillus chondroitinus NHase (PcNHase), Rhodococcus erythropolis NHase (ReNHase), Caballeronia jiangsuensis NHase (CjNHase), Gordonia hydrophobica NHase (GhNHase), and Bacillus sp. RAPc8 NHase (BrNHase) in the presence of $0.1 \mathrm{mM} \mathrm{CoCl}_{2}$ or $1 \mathrm{mM} \mathrm{FeSO}_{4}$ [9] (Figures S1 and S2). Bradyrhizobium japonicum NHase (BjNHase), Aurantimonas manganoxydans NHase (AmNHase) [13], and Pseudonocardia thermophila NHase (PtNHase) [14] were less well expressed. The Klebsiella oxytoca NHase (KoNHase) [8] showed imbalanced overexpression with significant amounts of the $\beta$-subunit but almost no $\alpha$-subunit. Nitriliruptor alkaliphilus NHase (NaNHase) [15] predominantly formed inclusion bodies and was detected in the insoluble fraction. A putative NHase from Rhizobium leguminosarum bv. trifolii (RlNHase) was found in the soluble fraction in minor amounts only when $1 \mathrm{mM}$ of $\mathrm{CoCl}_{2}$ was supplemented (Figure S5). Overexpression was also achieved for Afipia broomeae NHase (AbNHase), Comamonas testosteroni 5-MGAM NHase (CtNHase) [16], Roseobacter sp. MedPE-SWchi NHase (RmNHase), and Variovorax sp. CF313 (VvNHase) (Figure S3). The putative NHases from Ralstonia solanacearum (RsNHase) and from Tardiphaga robiniae (TrNHase) showed higher expression of the $\alpha$ - subunit as compared to the $\beta$-subunit. The iron-type NHase from Pseudomonas kilonensis (PkNHase) was well expressed whereas the NHase from Acinetobacter baylyi (AcNHase) was found neither in the soluble nor in the insoluble fraction. Pseudomonas marginalis NHase (PmNHase) showed imbalanced expression with higher amount of the $\beta$-subunit (Figure S3).

\subsection{Activity for Methacrylonitrile and Characterization of $p H$ Optimum and Stability}

Cell free extracts (CFE) were subsequently used to investigate whether the NHases were capable to hydrolyze a typical NHase substrate, methacrylonitrile (MAN, 1a) [17]. This conversion can conveniently be monitored in a plate reader, allowing efficient investigation of the effect of different reaction parameters, and was therefore applied where appropriate. Table 1 shows that expression levels do not necessarily correlate with activities. This fact indicates that some NHases may be particularly 
active on small aliphatic substrates like MAN (e.g., ReNHase) whereas others might prefer substrates of different chemical structure (e.g., GhNHase, which is produced in high amounts but does not hydrate MAN very well, see Table 1) Similarly, Co-dependent KoNHase readily produced methacryloamide, whereas MlNHase, although better expressed, was not as efficient with MAN as the substrate. Hence, we expected diverging substrate specificities of the NHase panel. Outstanding activities for the substrate MAN were obtained with the two iron-dependent NHases from R. erythropolis and P. kilonensis and the two cobalt-dependent NHases from K. oxytoca and C. testosteroni. The activities in relation to the amount of NHase, which was estimated from gel pictures, revealed also Co-type NaNHase, and Fe-type GhNHase and PmNHase as promising candidates.

Table 1. Screening cell free extracts for nitrile hydratase activity towards hydrolysis of methacrylonitrile.

\begin{tabular}{|c|c|c|c|}
\hline NHase & $\begin{array}{c}\text { Estimated NHase Content } \\
\text { in CFE }[\mathrm{mg} / \mathrm{mL}]\end{array}$ & $\begin{array}{c}\text { Activity } \\
{\left[\mu \mathrm{mol} \mathrm{min}^{-1} \mathrm{mg}^{-1}\right]^{1}}\end{array}$ & 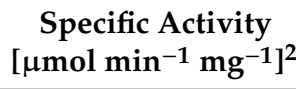 \\
\hline Fe-type $A c$ NHase & $<0.1$ & 3 & 0 \\
\hline Fe-type GhNHase & 3.4 & 18 & 55 \\
\hline Fe-type $P k N H a s e$ & 2.9 & 182 & 615 \\
\hline Fe-type $P m$ NHase & 1.9 & 52 & 313 \\
\hline Fe-type ReNHase & 2.9 & 248 & 605 \\
\hline Co-type $A b$ NHase & 1.6 & 14 & 53 \\
\hline Co-type AmNHase & 0.8 & 3 & 37 \\
\hline Co-type BjNHase & 0.1 & 2 & 14 \\
\hline Co-type BrNHase & 0.1 & 4 & 20 \\
\hline Co-type CjNHase & 2.9 & 23 & 88 \\
\hline Co-type CtNHase & 3.4 & 118 & 336 \\
\hline Co-type KoNHase & 2.9 & 165 & 613 \\
\hline Co-type MlNHase & 3.9 & 30 & 98 \\
\hline Co-type $\mathrm{NaNHase}$ & 1.0 & 62 & 505 \\
\hline Co-type PcNHase & 1.7 & 1 & 5 \\
\hline Co-type PtNHase & 1.2 & 41 & 243 \\
\hline Co-type RlNHase ${ }^{3}$ & 0.4 & 0 & 0 \\
\hline Co-type $R m$ NHase & 4.2 & 45 & 138 \\
\hline Co-type RsNHase & 2.0 & 0 & 0 \\
\hline Co-type $\operatorname{TrNHase}$ & 1.7 & 1 & 3 \\
\hline Co-type $V v$ NHase & 1.5 & 8 & 54 \\
\hline
\end{tabular}

${ }^{1}$ Activity relates to total protein content of the cell free extract (CFE). ${ }^{2}$ Specific activity calculated on basis of estimated NHase content in CFE. ${ }^{3}$ Addition of $1 \mathrm{mM}$ of $\mathrm{CoCl}_{2}$ at induction.

The spectrophotometric MAN assay was used to determine biochemical characteristics of seven selected NHases. The effect of $\mathrm{pH}$ is summarized in Figure 3. Fe-dependent NHases showed good activities between $\mathrm{pH} 6.0$ and 8.0, but already $\mathrm{pH} 8.5$ fully abolished activity. Co-dependent NHases tolerated a broader $\mathrm{pH}$ range, although activities decreased significantly above $\mathrm{pH} 8.5$.

In view of future applications, the operational stability of the enzymes is an important parameter. Therefore, the NHase containing CFEs were incubated at $37^{\circ} \mathrm{C}$ and $50^{\circ} \mathrm{C}$, respectively. Residual activity was determined after 1 and 6 h, respectively. As shown in Figure 4a, CtNHase and KoNHase retained full activity when incubated at $37^{\circ} \mathrm{C}$, whereas all other NHases were deactivated to some degree upon incubation (Figure 4a). The effect was even more pronounced upon treatment at $50^{\circ} \mathrm{C}$. This temperature was only tolerated by $\mathrm{C} t \mathrm{NHase}$ to some extent (Figure $4 \mathrm{~b}$ ). 


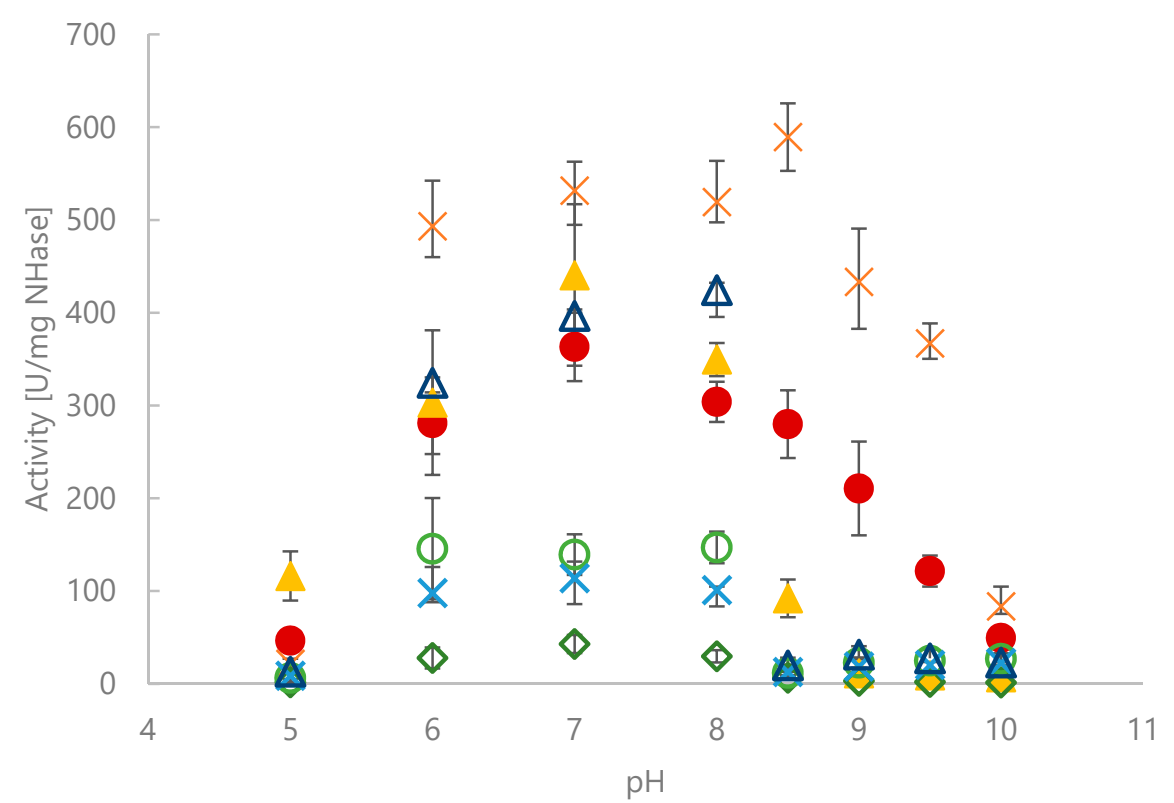

Figure 3. Activities of NHase CFEs for MAN hydrolysis at different $\mathrm{pH}$ values and $25{ }^{\circ} \mathrm{C}$. Citrate-phosphate buffer $\mathrm{pH}$ 5-6, sodium phosphate buffer $\mathrm{pH} 7-8$, Tris- $\mathrm{HCl}$ buffer $\mathrm{pH}$ 8.5, carbonate buffer $\mathrm{pH}$ 9-10. CtNHase: filled dark red circles. KoNHase: filled orange squares. NaNHase: filled yellow triangles. GhNHase: green rhombs. PkNHase: light green circles. PmNHase: blue crosses. ReNHase: dark blue triangles.

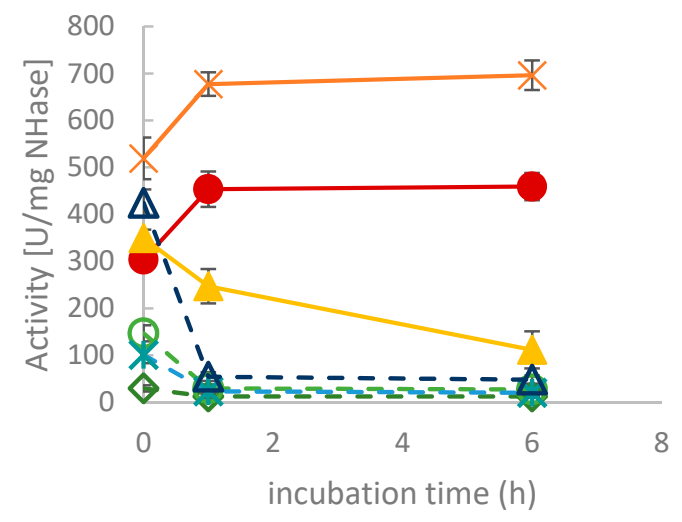

(a)

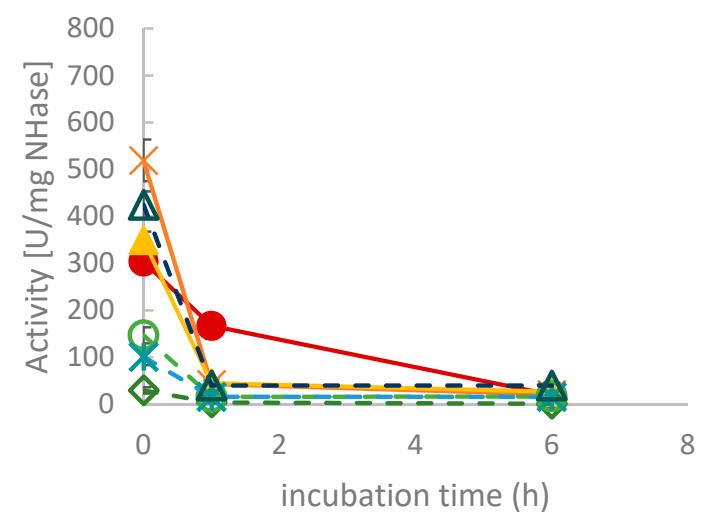

(b)

Figure 4. Residual activities of NHase CFEs for MAN hydrolysis at $25^{\circ} \mathrm{C}$. (a) After incubation at $37^{\circ} \mathrm{C}$ in buffer at $\mathrm{pH} 8.0$; (b) after incubation at $50{ }^{\circ} \mathrm{C}$ at $\mathrm{pH}$ 8.0. CtNHase: filled dark red circles. KoNHase: filled orange squares. NaNHase: filled yellow triangles. GhNHase: green rhombs, dashed line. $P k N H a s e:$ light green circles, dashed line. PmNHase: blue crosses, dashed line. ReNHase: dark blue triangles, dashed line.

To investigate whether activity loss was caused by the denaturation of the NHases, the proteins in form of CFEs were treated at $37^{\circ} \mathrm{C}$ and $50^{\circ} \mathrm{C}$ for $16 \mathrm{~h}$, respectively. After centrifugation, the soluble fraction was analyzed by SDS-PAGE. P $m$ NHase and $P k N H$ ase had almost completely precipitated at both temperatures (Figure S4). The soluble amounts of CtNHase, KoNHase, GhNHase and NaNHase decreased upon incubation, especially at $50{ }^{\circ} \mathrm{C}$. Remarkably, the amount of soluble ReNHase remained constant, which indicates that aggregation was not the reason for activity loss of this particular NHase. 


\subsection{Exploration of Substrate Scope}

To evaluate the potential of the NHase panel further, we selected structurally diverse nitriles and used them as substrates in biotransformations with cell free extracts. The conversion of pyrazine-2-carbonitrile (2a) gives pyrazine-2-carboxamide, which is known to be an antitubercular agent [18]. All NHases were included in this screening for activity. Conversions were determined by high performance liquid chromatography (HPLC) with mass selective detection (MS). Initial experiments gave full conversion of $\mathbf{2 a}$ with all NHase CFEs. To identify differences, we diluted the protein preparations and shortened reaction times. Indeed, a ranking of biocatalysts was then feasible and four NHase CFEs gave $>99 \%$ conversion (CtNHase, KoNHase, PkNHase and PmNHase) (Figure 5a). Considering the varying amounts of NHase in the respective CFE, Figure 5b shows a comparison with normalized amounts of NHase. Therefore, expression levels were estimated from gel pictures. For 2a, the NHase from Pseudonocardia thermophila is the most active NHase of the group of Co-dependent enzymes and Pseudomonas marginalis the most efficient amongst Fe-dependent NHases.

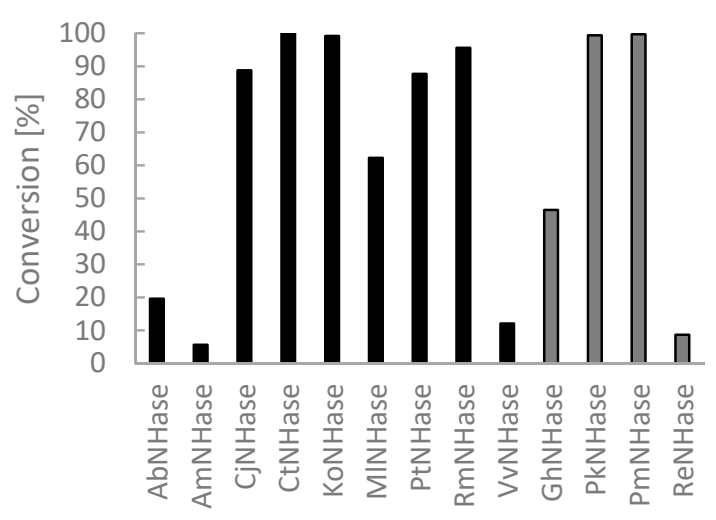

(a)

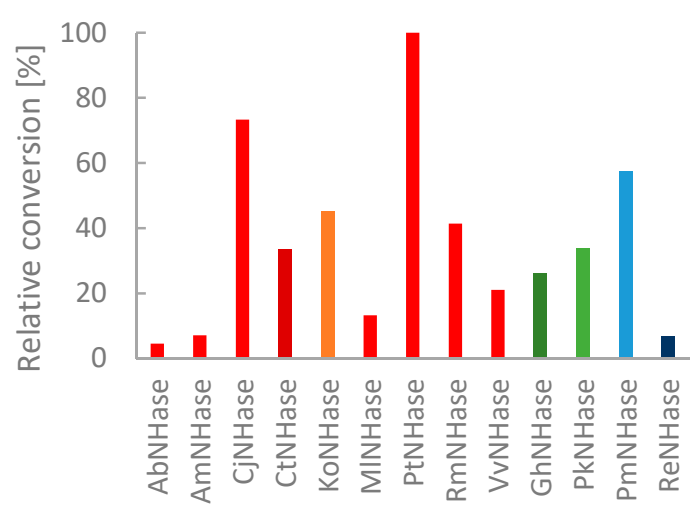

(b)

Figure 5. (a) Amide formation from $5 \mathrm{mM}$ 2a with NHase CFEs (1:200 dilution) in $100 \mathrm{mM} \mathrm{KH}_{2} \mathrm{PO}_{4}$ buffer at pH 7.2 and $25^{\circ} \mathrm{C}$. Reaction time $5 \mathrm{~min}$. NaNHase was not included. Calculation was based on area normalization. All omitted NHases were inactive for 2a hydration under these conditions. Black: Co and Grey Fe-dependent NHases; (b) Relative activities of NHases. Red tones: Co- and Green/Blue Fe-dependent NHases.

3-Amino-3-(p-toluoyl)propanenitrile (3a) belongs to the group of $\beta$-amino nitriles whose corresponding amides are of great pharmaceutical importance as they serve as building blocks for the synthesis of both biologically active peptides and small molecule pharmaceuticals. Both 3a and 2a have previously been successfully subjected to enzymatic hydration using a $R$. rhodochrous nitrile hydratase $[19,20]$. $\beta$-Amino nitriles can also be transformed to amides and carboxylic acids with protective groups on the $\beta$-amino group using the native NHase and amidase expressing host organisms [21-23]. Normalized on NHase content, Pseudonocardia thermophila and Pseudomonas marginalis showed high potential for the conversion of this primary amine containing substrate 3-amino-3-(p-tolyl)propanenitrile (3a) (Figure 6a). When equal amounts of CFEs were used, 3a was fully converted to the respective amide by $\mathrm{C} t \mathrm{NHase}$, due to its exceptional expression level (data not shown). 


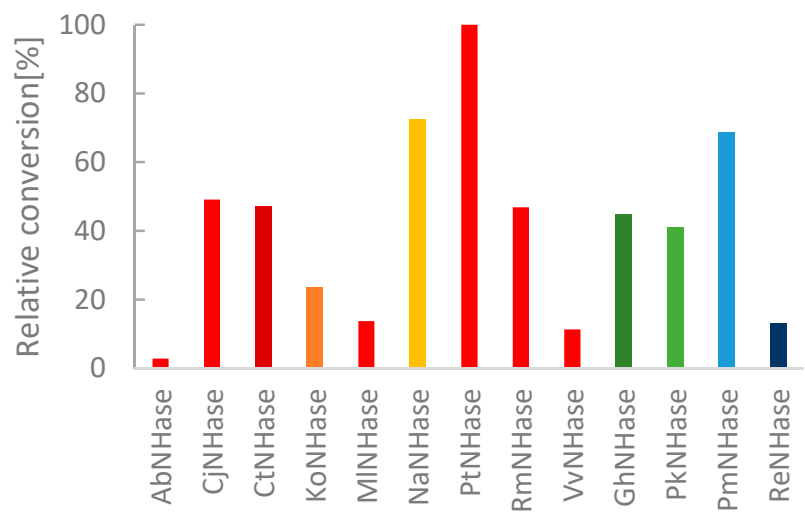

(a)

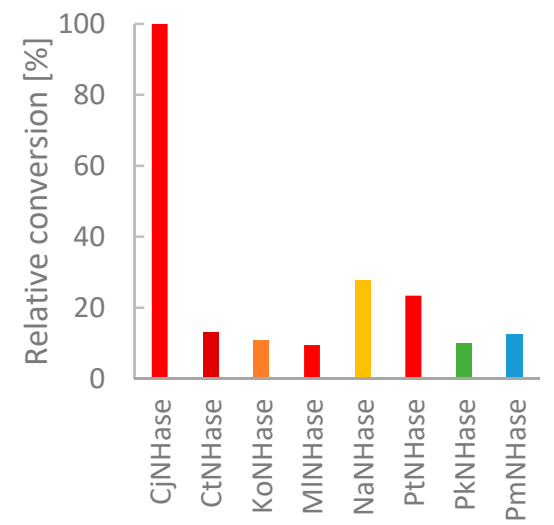

(b)

Figure 6. Amide formation from $5 \mathrm{mM}$ substrate. Reaction time $5 \mathrm{~min}$. Red tones: Co- and Green/Blue Fe-dependent NHases. (a) 3a with NHase CFEs (1:200 dilution) in $100 \mathrm{mM} \mathrm{KH}_{2} \mathrm{PO}_{4}$ buffer at pH 7.2 and $25{ }^{\circ} \mathrm{C}$. All missing NHases were inactive for 3a hydration under these conditions. (b) $4 \mathbf{a}$ with NHase CFEs (1:100 dilution) in $273 \mathrm{mM} \mathrm{Na}_{2} \mathrm{HPO}_{4} / 72 \mathrm{mM} \mathrm{NaH}_{2} \mathrm{PO}_{4}$ at $\mathrm{pH}$ 7.5. All omitted NHases were inactive for $4 \mathrm{a}$ hydration under these conditions.

To extend the structural scope of substrates, we furthermore looked into the capability of the NHases to convert the unsaturated cinnamic acid nitrile (4a) [24]. Of all NHases, CjNHase showed clearly outstanding activity for compound $4 \mathbf{a}$ (Figure $6 \mathrm{~b}$ ). For 3a, CjNHase showed only little activity (Figure 6a) and for 2a, the enzyme was good, but not excellent (Figure 5b). A much less pronounced trend was observed for compound 3a, which was hydrated to a high degree by Co-dependent $\mathrm{C} t \mathrm{NH}$ ase, $\mathrm{R} m \mathrm{NH}$ ase and $\mathrm{PtNHase}$, but also by the Fe-dependent $P m$ NHase. The heterocyclic pyrazine nitrile $2 \mathrm{a}$, was converted very efficiently by seven NHases of both types. A concentration of $5 \mathrm{mM}$ pyrazine-2-carbonitrile (2a) could, for example, be fully hydrated by only $9 \mu \mathrm{g} / \mathrm{mL}$ KoNHase in the reaction mixture within less than $5 \mathrm{~min}$. Similarly, $12 \mu \mathrm{g} / \mathrm{mL} C t$ NHase produced $5 \mathrm{mM}$ of $3 \mathbf{b}$ and 10 $\mu \mathrm{g} / \mathrm{mL}$ C $j$ NHase $5 \mathrm{mM}$ of $\mathbf{4 b}$.

The screening results with methacrylonitrile (1a) (Table 1) agreed with these end-point measurements in terms of unsuitable NHases (those with low activities for MAN were generally also poor for other substrates). The MAN assay is a suitable tool to quickly reveal highly active NHase preparations capable of converting other nitriles efficiently as well, although this assay may overestimate the potential of NHases with a particular preference for small, aliphatic nitriles.

In conclusion, cobalt-dependent nitrile hydratases seem to be more abundant in nature as compared to the respective iron-dependent counterparts, as judged by their much higher prevalence in public databases. Herein we extended the chemists' toolbox for enzymatic amide formation from nitrile precursors and associated experimentally confirmed function to more than a dozen putative NHases. Functional expression of NHases was done in the presence of their native accessory proteins under the control of the tac promoter. Gentle expression at low temperature and supply of active site metal was important. Nevertheless, expression levels strongly varied: whereas some NHases gave high content of soluble protein, the majority of the investigated proteins gave medium levels and only few gave levels close to the detection limit. Of the four new Fe-dependent NHases, three showed promising activity for the four investigated substrates. Fe-dependent NHases were active in the $\mathrm{pH}$ range between $\mathrm{pH}$ 6.0-8.0. By contrast, Co-dependent NHases were tolerant to a much broader $\mathrm{pH}$ range up to $\mathrm{pH}$ 9.5. We did not observe a strict substrate preference indicating broad applicability of both Fe- and Co-dependent nitrile hydratases. 


\section{Materials and Methods}

\subsection{General}

Tris was purchased from Carl Roth (Karlsruhe, Germany), isopropyl $\beta$-D-1-thiogalactopyranoside (IPTG) from Serva (Heidelberg, Germany), methacrylonitrile from Fluka (Buchs, Switzerland) and $\mathrm{CoCl}_{2}$ and $\mathrm{FeSO}_{4}{ }^{*} 7 \mathrm{H}_{2} \mathrm{O}$ from Merck. HPLCMS grade acetonitrile was purchased from J.T.Baker/Avantor Performance Materials (Deventer, The Netherlands). All other chemicals were obtained from Sigma-Aldrich (St. Luis, MO, USA) and used without further purification.

E. coli cells were cultivated in an RS 306 shaker (Infors, Bottmingen, Switzerland), a Multitron shaker (Infors AG Bottmingen, Switzerland) and a Certomat BS-1, and the cells were harvested with an Avanti J-20 XP centrifuge (Beckman Coulter, Brea, CA, USA). Cell pellets were disrupted by a 102C converter with a Sonifier 250 (Branson, Danbury, CT, USA), and the cell-free extract was obtained by centrifugation in an Avanti J-20 XP centrifuge (Beckman Coulter). Reactions were performed on a Thermomixer comfort (Eppendorf, Hamburg, Germany). HPLC/MS analysis was carried out on an Agilent Technologies (Santa Clara, CA, USA) 1200 Series equipped with G1379B degasser, G1312B binary pump SL, G1367C HiP-ALS SL autosampler, a G1314C VWD SL UV detector, G1316B TCC SL column oven and a G1956B MSD. A positive electrospray ionization mode was used as ionization method.

\subsection{Sequence Identification and Cloning}

Bradyrhizobium japonicum NHase (BjNHase; BAC49763.1 and WP_028174056.1) was used as a template to search for Co-type NHases whereas for Fe-containing NHases Rhodococcus erytrhopolis NHase (ReNHase) served as the template for a blastp search against the Gen-Bank non-redundant protein sequences. Sequences were selected based on the following criteria (partly from literature): Presence of activator gene, stability, and probability of efficient expression in E. coli. The following sequences were chosen: Pseudomonas marginalis NHase (PmNHase; WP_074846646.1 and WP_074846644.1), Acinetobacter baylyi NHase (AcNHase; ENV54396.1 and ENV54397.1), Gordonia hydrophobica NHase (GhNHase; WP_066163464.1 and WP_066163466.1), Tardiphaga robiniae NHase (TrNHase; KZD20487.1 and KZD20486.1), Bacillus sp. NHase (BrNHase: AAO23015.1 and AAO23014.1), Nitriliruptor alkaliphilus NHase (NaNHase: WP_052668589.1 and WP_052668588.1), Pseudonocardia thermophila NHase (PtNHase; WP_073455624.1 and WP_073455623.1), Paenibacillus chondroitinus NHase (PcNHase: WP_047675415.1 and WP_047675418.1), Comamonas testosteroni NHase (CtNHase; AAU87542.1 and AAU87543.1), Klebsiella oxytoca NHase (KoNHase; OSY94202.1 and WP_0109240358.1), Roseobacter sp. NHase (RmNHase: OIQ35619.1 and OIQ35618.1), Ralstonia solanacearum NHase (RsNHase; AMP38431.1 and AMP38430.1), Afipia broomeae NHase (AbNHase; EKS37369.1 and EKS37368.1), Variovorax sp. NHase (VvNHase; WP_042672800.1 and WP_007829432.1), Microvirga lotononidis NHase (MlNHase; EIM25394.1 and EIM25395.1), Aurantimonas manganoxydans NHase (AmNHase; WP_009208459.1 and WP_009208458.1), Rhizobium leguminosarum NHase (RlNHase; EJC80161.1 and EJC80160.1), and Caballeronia jiangsuensis NHase (CjNHase; WP_035501544.1 and WP_035501545.1).

NHase operons comprise of three open reading frames (nhA, nhB and activator) which are often overlapping. Most genes were ordered at IDT (Coralville, IA, USA), GenScript (Piscataway, NJ, USA) and ThermoFisher Scientific (Waltham, MA, USA) beginning with the start codon ATG of the first subunit and ending with one of the two stop codons TGA/TAA of the activator with overhangs for Gibson assembly with linearized pMS470 vector. The genes encoding CjNHase, GhNHase, and PtNHase were purchased in codon optimized form. E. coli Top10F' were transformed, colonies selected on LB-Amp and colony PCR (polymerase chain reaction) and/or control cuts of isolated plasmids were used to identify positive clones. After sequencing, E. coli BL21 (DE3) Gold was transfected with the respective plasmids. 


\subsection{Protein Expression}

The strains were cultured at $37{ }^{\circ} \mathrm{C}$ in LB-Amp and induction was performed at an optical density at $600 \mathrm{~nm}\left(\mathrm{OD}_{600}\right)$ of $0.8-1.0$ with $0.1 \mathrm{mM}$ IPTG and $1 \mathrm{mM}$ or $2.5 \mathrm{mM} \mathrm{FeSO}_{4} * 7 \mathrm{H}_{2} \mathrm{O}, 0.1 \mathrm{mM}$ or $1 \mathrm{mM}$ $\mathrm{CoCl}_{2}$ at $20^{\circ} \mathrm{C}$. Pellets were harvested by centrifugation after $\sim 24 \mathrm{~h}$ and analyzed after cell disruption with BugBuster reagent by SDS-PAGE.

Cell free extracts (CFE) for biotransformation reactions were prepared as follows: Cultivation was performed as described above, typically in a total volume of $400 \mathrm{~mL}$ LB medium, using $1 \mathrm{~L}$ baffled Erlenmeyer flasks. Cells were harvested by centrifugation at 5,000 $\mathrm{g}$ and $4{ }^{\circ} \mathrm{C}$ for $15 \mathrm{~min}$. The supernatant was discarded and 1.2-3.0 g of pellets were resuspended in $25 \mathrm{~mL}$ of $50 / 40 \mathrm{mM}$ Tris-butyrate buffer, $\mathrm{pH} 7.2$, and lysed on ice by sonication for $6 \mathrm{~min}$ at $70-80 \%$ duty cycle and $7-8$ output control. Cell-free extracts were obtained after centrifugation for $1 \mathrm{~h}$ at $48,250 \times g\left(1 \mathrm{mM} \mathrm{FeSO}_{4^{*}} 7 \mathrm{H}_{2} \mathrm{O}\right.$ and $0.1 \mathrm{mM} \mathrm{CoCl} 2$ samples) or 20,000 $\mathrm{g}\left(2.5 \mathrm{mM} \mathrm{FeSO}_{4} * \mathrm{H}_{2} \mathrm{O}\right.$ and $1 \mathrm{mM} \mathrm{CoCl}$ samples). The temperature was $4{ }^{\circ} \mathrm{C}$ and samples were filtered through $0.45 \mu \mathrm{m}$ syringe filters. Protein concentration was determined using the Pierce ${ }^{\mathrm{TM}}$ BCA Protein Assay Kit (ThermoFisher).

\subsection{Spectrophotometric MAN Assay}

Physicochemical characteristics of NHases were determined by monitoring the hydrolysis of methacrylonitrile (MAN, 1a). Therefore, $10 \mu \mathrm{L}$ NHase-CFE (diluted in Tris/butyrate buffer 50/40 mM pH 7.2) were mixed with $100 \mu \mathrm{L}$ of $125 \mathrm{mM}$ MAN in Tris/butyrate buffer 50/40 mM (pH 7.2) in 96-well UV star plates. The formation of methacrylamide (MAD, $\mathbf{1 b}$ ) was monitored at $224 \mathrm{~nm}$ on a Synergy Mx Plate-reader (BioTek Instruments, Winooski, USA) at $25^{\circ} \mathrm{C}$ for $5 \mathrm{~min}$. The Units of the sample can be calculated with Equation (1):

$$
\frac{U}{\mathrm{ml}}=\frac{\text { Velocity }\left(\mathrm{min}^{-1}\right) \times 0.11 \mathrm{~mL} \times \text { dilution }}{2.551 \mathrm{mMcm}^{-1} \times 0.1 \mathrm{~mL} \times \text { pathlength }(\mathrm{cm})}
$$

Appropriate blank reactions were carried out in parallel and each reaction was carried out at least in triplicate.

For the determination of the $\mathrm{pH}$ optimum, the standard assay as described above was used with the following buffers: $100 \mathrm{mM}$ citrate-phosphate buffer $\mathrm{pH} 5-6,100 \mathrm{mM}$ sodium phosphate buffer $\mathrm{pH}$ 7-8, 100 mM Tris-HCl buffer $\mathrm{pH}$ 8.5, 100 mM carbonate buffer $\mathrm{pH}$ 9-10.

\subsection{Synthesis}

Racemic 3-amino-3-(p-toluoyl)propanenitrile (3a) was prepared as previously published and all analytical data corresponded [20]. The corresponding amide $\mathbf{3 b}$ was prepared as follows: A solution of rac-3-amino-3-(p-toluoyl)propanenitrile (3a, $30 \mathrm{mg}, 0.187 \mathrm{mmol})$ in $\mathrm{MeOH}(1 \mathrm{~mL})$ was added to a suspension of Rhodococcus rhodochrous ATCC BAA-870 [25] (30 mg wet weight cells) in $50 \mathrm{mM}$ Tris buffer ( $\mathrm{pH} 7.6,4 \mathrm{~mL}$ ). The mixture was stirred vigorously on a magnetic stirrer unit for $24 \mathrm{~h}$. Ethyl acetate $(5 \mathrm{~mL})$ was added and the mixture was vortexed well followed by centrifugation at $10,000 \times g$ for $10 \mathrm{~min}$. The top organic layer was dried over $\mathrm{MgSO}_{4}$, filtered and dried in vacuo to yield almost pure amide product. After trituration in hexane and filtration of the product, the racemic amide was obtained as a white solid (26 mg, 78\%). All analytical data corresponded to that previously published [20].

\subsection{Chromatographic Assay}

The typical assay to determine directly the reaction products was carried out as follows: $100 \mu \mathrm{L}$ NHase-CFE (16-96 $\mu \mathrm{g} / \mathrm{mL}$ for $\mathbf{2 a}$ and $\mathbf{3 a}, 32-192 \mu \mathrm{g} / \mathrm{mL}$ for $\mathbf{4 a}$ ) were mixed with $100 \mu \mathrm{L}$ substrate solution (10 mM of $\mathbf{2 a}, 3 \mathbf{a}$, or $4 \mathbf{a}$ in reaction buffer) and incubated for $5 \mathrm{~min}$ at $25^{\circ} \mathrm{C}$ and $350-450 \mathrm{rpm}$ in Eppendorf thermomixers. The reactions were stopped by the addition of $400 \mu \mathrm{L} \mathrm{MeOH} / \mathrm{HCOOH}$ (19:1). After centrifugation of precipitated protein, the supernatants were analyzed by HPLC. The nitriles were separated from amides by a Phenomenex (Torrance, USA) Kinetex $2.6 \mu$ m Biphenyl $100 \AA$ 
column $(150 \times 2.1 \mathrm{~mm}, 2.6 \mu \mathrm{m})$ using $5 \mathrm{mM}$ ammonium acetate solution and acetonitrile as the mobile phase, at a flow rate of $0.26 \mathrm{~mL} / \mathrm{min}$ for $15 \mathrm{~min}$. A gradient with increasing acetonitrile levels was used: $25-55 \%$ (5 min), 55-70\% (2 min, $20 \mathrm{~s}$ ), 70-90\% (30 s), 90\% (1 min, 10s), 90-25\% (1 s), 25\% (5 min, $59 \mathrm{~s}$ ). The compounds were detected at $210 \mathrm{~nm}$ (diode array detector).

Supplementary Materials: The following are available online at http://www.mdpi.com/1420-3049/25/11/2521/s1, Figure S1-S5: SDS-PAGE of NHases.

Author Contributions: Conceptualization, K.D., K.S., H.S. and M.W.; methodology, B.G., M.G. and D.P.; formal analysis, B.G., M.G., D.P. and M.W.; investigation, B.G., M.G. and D.P.; resources, K.D.; writing-original draft preparation, M.W.; writing—review and editing, B.G., M.G., H.S., K.S., K.D., D.B; visualization, M.W.; supervision, M.W. and D.B.; project administration, M.W.; funding acquisition, K.S. and H.S. All authors have read and agreed to the published version of the manuscript.

Funding: The COMET center acib: Next Generation Bioproduction is funded by BMK, BMDW, SFG, Standortagentur Tirol, Government of Lower Austria und Vienna Business Agency in the framework of COMET-Competence Centers for Excellent Technologies. The COMET-Funding Program is managed by the Austrian Research Promotion Agency FFG.

Conflicts of Interest: The authors declare no conflict of interest.

\section{References}

1. Prasad, S.; Bhalla, T.C. Nitrile hydratases (NHases): At the interface of academia and industry. Biotechnol. Adv. 2010, 28, 725-741. [CrossRef] [PubMed]

2. Mashweu, A.R.; Chhiba-Govindjee, V.P.; Bode, M.L.; Brady, D. Substrate Profiling of the Cobalt Nitrile Hydratase from Rhodococcus rhodochrous ATCC BAA 870. Molecules 2020, 25, 238. [CrossRef] [PubMed]

3. Zheng, R.-C.; Zheng, Y.-G.; Shen, Y.-C. Acrylamide, Microbial Production by Nitrile Hydratase. In Encyclopedia of Industrial Biotechnology; John Wiley and Sons, Inc.: Hoboken, NJ, USA, 2010; pp. 1-39.

4. Cheng, Z.; Xia, Y.; Zhou, Z. Recent Advances and Promises in Nitrile Hydratase: From Mechanism to Industrial Applications. Front. Bioeng. Biotechnol. 2020, 8. [CrossRef] [PubMed]

5. Supreetha, K.; Rao, S.N.; Srividya, D.; Anil, H.S.; Kiran, S. Advances in cloning, structural and bioremediation aspects of nitrile hydratases. Mol. Biol. Rep. 2019, 46, 4661-4673. [CrossRef]

6. Wu, S.; Fallon, R.D.; Payne, M.S. Over-production of stereoselective nitrile hydratase from Pseudomonas putida 5B in Escherichia coli: Activity requires a novel downstream protein. Appl. Microbiol. Biotechnol. 1997, 48, 704-708. [CrossRef] [PubMed]

7. Yukl, E.T.; Wilmot, C.M. Cofactor biosynthesis through protein post-translational modification. Curr. Opin. Chem. Biol. 2012, 16, 54-59. [CrossRef]

8. Guo, F.-M.; Wu, J.-P.; Yang, L.-R.; Xu, G. Overexpression of a nitrile hydratase from Klebsiella oxytoca KCTC 1686 in Escherichia coli and its biochemical characterization. Biotechnol. Bioprocess Eng. 2015, 20, 995-1004. [CrossRef]

9. Cameron, R.A.; Sayed, M.; Cowan, D.A. Molecular analysis of the nitrile catabolism operon of the thermophile Bacillus pallidus RAPc8. Biochim. Biophys. Acta 2005, 1725, 35-46. [CrossRef]

10. Miyanaga, A.; Fushinobu, S.; Ito, K.; Wakagi, T. Crystal Structure of Cobalt-Containing Nitrile Hydratase. Biochem. Biophys. Res. Commun. 2001, 288, 1169-1174. [CrossRef]

11. Pei, X.; Zhang, H.; Meng, L.; Xu, G.; Yang, L.; Wu, J. Efficient cloning and expression of a thermostable nitrile hydratase in Escherichia coli using an auto-induction fed-batch strategy. Process Biochem. 2013, 48, 1921-1927. [CrossRef]

12. Letunic, I.; Bork, P. Interactive Tree Of Life (iTOL) v4: Recent updates and new developments. Nucleic Acids Res. 2019, 47, W256-W259. [CrossRef] [PubMed]

13. Pei, X.; Yang, Z.; Wang, A.; Yang, L.; Wu, J. Identification and functional analysis of the activator gene involved in the biosynthesis of Co-type nitrile hydratase from Aurantimonas manganoxydans. J. Biotechnol. 2017, 251, 38-46. [CrossRef] [PubMed]

14. Yamaki, T.; Oikawa, T.; Ito, K.; Nakamura, T. Cloning and sequencing of a nitrile hydratase gene from Pseudonocardia thermophila JCM3095. J. Ferment. Bioeng. 1997, 83, 474-477. [CrossRef] 
15. Van Pelt, S.; Zhang, M.; Otten, L.G.; Holt, J.; Sorokin, D.Y.; van Rantwijk, F.; Black, G.W.; Perry, J.J.; Sheldon, R.A. Probing the enantioselectivity of a diverse group of purified cobalt-centred nitrile hydratases. Org. Biomol. Chem. 2011, 9. [CrossRef]

16. Petrillo, K.L.; Wu, S.; Hann, E.C.; Cooling, F.B.; Ben-Bassat, A.; Gavagan, J.E.; DiCosimo, R.; Payne, M.S. Over-expression in Escherichia coli of a thermally stable and regio-selective nitrile hydratase from Comamonas testosteroni 5-MGAM-4D. Appl. Microbiol. Biotechnol. 2005, 67, 664-670. [CrossRef]

17. Murakami, T.; Nojiri, M.; Nakayama, H.; Dohmae, N.; Takio, K.; Odaka, M.; Endo, I.; Nagamune, T.; Yohda, M. Post-translational modification is essential for catalytic activity of nitrile hydratase. Protein Sci. 2000, 9, 1024-1030. [CrossRef] [PubMed]

18. Zhou, S.; Yang, S.; Huang, G. Design, synthesis and biological activity of pyrazinamide derivatives for anti-Mycobacterium tuberculosis. J. Enzyme Inhib. Med. Chem. 2017, 32, 1183-1186. [CrossRef]

19. Mauger, J.; Nagasawa, T.; Yamada, H. Nitrile hydratase-catalyzed production of isonicotinamide, picolinamide and pyrazinamide from 4-cyanopyridine, 2-cyanopyridine and cyanopyrazine in Rhodococcus rhodochrous J1. J. Biotechnol. 1988, 8, 87-95. [CrossRef]

20. Chhiba, V.; Bode, M.L.; Mathiba, K.; Kwezi, W.; Brady, D. Enantioselective biocatalytic hydrolysis of $\beta$-aminonitriles to $\beta$-amino-amides using Rhodococcus rhodochrous ATCC BAA-870. J. Mol. Catal. B Enzym. 2012, 76, 68-74. [CrossRef]

21. Preiml, M.; Hillmayer, K.; Klempier, N. A new approach to beta-amino acids: Biotransformation of N-protected beta-amino nitriles. Tetrahedron Lett. 2003, 44, 5057-5059. [CrossRef]

22. Preiml, M.; Hönig, H.; Klempier, N. Biotransformation of $\beta$-amino nitriles: The role of the N-protecting group. J. Mol. Catal. B Enzym. 2004, 29, 115-121. [CrossRef]

23. Mareya, T.M.; Coady, D.T.M.; O’Reilly, D.C.; Kinsella, D.M.; Coffey, D.L.; Lennon, D.C.M. Process Optimisation Studies and Aminonitrile Substrate Evaluation of Rhodococcus erythropolis SET1, A Nitrile Hydrolyzing Bacterium. ChemistryOpen 2020, 9. [CrossRef] [PubMed]

24. Cowan, D.; Cramp, R.; Pereira, R.; Graham, D.; Almatawah, Q. Biochemistry and biotechnology of mesophilic and thermophilic nitrile metabolizing enzymes. Extremophiles 1998, 2, 207-216. [CrossRef] [PubMed]

25. Frederick, J.; Hennessy, F.; Horn, U.; de la Torre Cortés, P.; van den Broek, M.; Strych, U.; Willson, R.; Hefer, C.A.; Daran, J.-M.G.; Sewell, T.; et al. The complete genome sequence of the nitrile biocatalyst Rhodococcus rhodochrous ATCC BAA-870. BMC Genomics 2020, 21, 3. [CrossRef] [PubMed]

Sample Availability: Samples of the compounds $\mathbf{3} \mathbf{a}$ and $\mathbf{3 b}$ are available from the authors.

(C) 2020 by the authors. Licensee MDPI, Basel, Switzerland. This article is an open access article distributed under the terms and conditions of the Creative Commons Attribution (CC BY) license (http://creativecommons.org/licenses/by/4.0/). 